\title{
El discurso peritextual en el libro ilustrado infantil y juvenil'
}

The Peritextual discourse in illustrated books for children

\author{
ELENA CONSEJO PANO \\ Universidad de Zaragoza \\ España \\ econsejo@unizar.es
}

(Recibido I6--12-20I3; aceptado I4-IO-20I4)

Resumen. El presente artículo es fruto de una reflexión sobre la evolución del libro ilustrado infantil y juvenil como objeto en sí mismo, un objeto que traspasa límites y se reinventa día tras día. Nos centramos en cómo autores y editores trasgreden estándares y quiebran normas editoriales y de encuadernación consideradas inamovibles por la tradición, transformando los peritextos (Genette, 200I) en piezas clave en el juego de la reconstrucción de sentidos.

Palabras clave: Literatura infantil ilustrada; peritextos; libro-objeto; competencia lectora; competencia literaria.
Abstract. This article is the result of a reflection on the evolution of illustrated children's books, considering the book as an object in itself, an object that oversteps limits and that is reinvented day after day. We focus on how authors and editors transgress standards and break book binding rules that were considered as immovable by tradition, transforming peritexts (Genette, 200I) into key components for the reconstruction of meanings.

Keywords: Illustrated children's literature; peritexts; book-object; reading competence; literary competence.

\footnotetext{
I Para citar este artículo: Consejo Pano, Elena (20I4). El discurso peritextual en el libro ilustrado infantil y juvenil. Álabe 10. [www.revistaalabe.com]

DOI io.I5645/Alabe.20I4.IO.6
} 


\section{I - Introducción}

El libro es un objeto cotidiano, común, no periódico, colectivo y coleccionable. Sus más de 49 páginas siempre integran un volumen. Este objeto queda definido por el Diccionario de la Lengua Española (2OOI) en sus dos primeras acepciones como: "Conjunto de muchas hojas de papel u otro material semejante que, encuadernadas, forman un volumen” y "Obra científica, literaria o de cualquier otra índole con extensión suficiente para formar volumen, que puede aparecer impresa o en otro soporte”. Esta simplicidad con que define el libro la RAE contrasta con la opinión de muchos al definir el objeto como una compleja estructura de arquitectura perfecta. De hecho, si atendemos a los elementos que constituyen un libro, veremos que se emplea una cierta terminología "arquitectónica": portada, portadilla, frontis, frontispicio, pórtico (del prólogo), friso, columnas, cornisa. Y aunque estos términos se sigan utilizando, sus formas y funciones primigenias se han ido transformando con el pasar de los tiempos y aún hoy podemos garantizar que siguen en plena evolución. Encontramos que dicha transformación atiende a diferentes causas. Por una parte, podríamos referirnos a una cuestión histórica en cuanto a la innovación y mejora de los materiales y medios que actúan en la elaboración de los libros. Por otra parte, creemos firmemente que estos cambios que detectamos, principalmente en el panorama actual de la literatura infantil ilustrada, son debidos a una nueva concepción del libro como objeto y, en concreto, de sus espacios peritextuales, concepción que encierra cierto carácter trasgresor en cuanto que rompe con los patrones editoriales y de encuadernación que dicta la práctica habitual.

\section{La cuestión histórica.}

La historia del libro va ligada incuestionablemente a la historia del hombre. El antepasado del libro actual surge de aquellos escritos romanos elaborados sobre hojas de pergamino cuadradas (simulando las antiguas tablillas de arcilla o madera) que, protegidas por tablas de cedro envueltas en cuero, se sujetaban con un cordel o con correas ajustadoras. Más adelante se comenzó a coser las hojas con nervios de animales para que no se perdieran o desordenaran. Este conjunto de páginas individuales, unidas por una costura y encuadernadas es lo que se denominó liber quadratus o codex. Así surge la encuadernación: fruto de la necesidad de procurar una buena conservación, un fácil manejo y una determinada presentación artística.

A mediados del s. XV con la aparición de la imprenta y los incunables, el libro fue adquiriendo paulatinamente la genética actual a la par que el acceso a la cultura se iba democratizando. Tanto Escarpit (I972) como Díaz-Plaja (I973) consideran que la imprenta llegó a su debido tiempo "lo cual demuestra que la innovación técnica sólo se impone cuando responde a una necesidad social” (Escarpit, I972:20). La incipiente "producción en masa" que supuso la imprenta consagró el papel sobre el pergamino y obligó a sustituir las pesadas tablas de madera por un material menos costoso y más ligero: el cartón.

Conforme la imprenta iba llegando a su madurez, los impresos se distanciaban de 
los manuscritos medievales y se consolidaban algunas fórmulas que serían esenciales en la apariencia del libro moderno: la paginación (heredera de la foliación y las signaturas tipográficas de los primeros años), la desaparición del texto dividido en dos columnas, el nacimiento de la portada y la marca de impresor, la letrería tipográfica, la incorporación de las ilustraciones y, por supuesto, las mejoras en la encuadernación, entre otras.

Los estilos imperantes de cada época fueron modificando sobre todo las tapas de los volúmenes incorporando en ellas desde esmaltes y piedras preciosas hasta pieles labradas policromadas o doradas. Así, movimientos artísticos tan relevantes como el Renacimiento, el Barroco, el Rococó, el Neoclásico o el Romanticismo fueron dejando huella en el diseño de las cubiertas y los lomos de los libros. Poco a poco los cosidos se fueron disimulando obteniendo encuadernaciones más suaves y las guardas (cuya función primordial era la de brindar una protección adicional al libro y ocultar el cosido) se comenzaron a decorar con papeles realizados para la ocasión a partir de diferentes técnicas como los amarmolados, empastados, estampados o en relieve, incluso se utilizaron guardas de cuero o seda elaboradamente decoradas. De hecho, desde principios de siglo XX, en ciertas ediciones se ilustraban las guardas aun cuando el libro no fuera especialmente ilustrado con el afán de rellenar los espacios que ofrecían estos pliegos.

Debido a la mecanización e industrialización de este arte, los encartonados o encuadernación cartoné (con tapas rígidas de cartón recubiertas tanto en los planos como en la lomera de papel, tela o piel) y las encuadernaciones de lujo (herederas de aquellas ostentosas obras de arte trabajadas con oro, marfil y finas piedras) tuvieron que ceder una gran porción de terreno a la encuadernación a la rústica en la que el volumen se protege simplemente por un forro de papel grueso, suplantando así otros materiales como fueron en su época el cuero, la tela o el pergamino. En la mayoría de los casos se trata de satisfacer una demanda de libros de consumo rápido y baratos. Este tipo de encuadernaciones de tapas flexibles y menor tamaño son también conocidas como libros de tapa blanda o libros de bolsillo. No llevan guardas y con frecuencia carecen incluso de otros elementos configurativos como la portadilla o las páginas de cortesía: lógico si lo que se pretende es abaratar el producto.

\section{Un nuevo concepto de libro como objeto.}

No cabe duda de que el objeto libro no ha cesado en su búsqueda de la perfección a la par que se ha adaptado a los nuevos devenires de la humanidad y del mercado.

También el libro ilustrado infantil ha ido adaptándose a los nuevos tiempos y a los nuevos lectores, en especial, el álbum ilustrado, género que acoge a la perfección la experimentación formal y semántica y que ha producido numerosa literatura a este respecto. Muchos son los autores que han profundizado en la complejidad del fenómeno (Nodelman, I988; Muñoz Tébar y Silva-Díaz (Eds.), I999; Lewis, 20oI; Nikolajeva y Scott, 20oI; Silva-Díaz, 2005; Ramos, 2007; Van der Linden, 2007; Sipe y Pantaleo, 2008; Durán, 20o9; Colomer, Kümmerling-Meibauer y Silva-Díaz , 2OIO) y que bajo la denominación de álbum ilustrado, picture book o picturebook no han dudado en considerarlo un arte- 
facto con potencial suficiente para modificar inercias y desafiar cánones, a la vez que se ha calificado de heterodoxo, camaleónico, híbrido, multimodal, sofisticado, omnívoro o polifónico.

En el presente artículo nos centraremos en cómo los peritextos de algunas obras de LIJ, alejándose de aquellos que definiera en su día Genette (2OOI), han adoptado otras formas y otras funciones diferentes a las marcadas por la tradición consiguiendo transformar el objeto en un todo en el que cualquier espacio es susceptible de concebirse como estrategia narrativa.

\section{2 - Puntos de partida}

Además de los autores ya mencionados que han teorizado sobre la construcción, evolución y conceptualización del álbum actual, señalamos aquí otros trabajos que han tratado en mayor o menor medida los peritextos en el discurso literario infantil y juvenil.

Obviamente partimos de los términos acuñados por Genette referentes a la paratextualidad (I989, 200I) y a los que nos referiremos más detenidamente en el siguiente apartado.

Consideramos imprescindibles los numerosos estudios que el profesor Lawrence Sipe de la Universidad de Pensilvania publicó sobre los álbumes, sus peritextos y las respuestas lectoras que estos provocaban en jóvenes lectores. Entre ellos destacamos su artículo Picturebooks as aesthetic objects (2OOI) y los realizados con sus colegas Brightman (2005) y McGuire (2006).

A su vez, otros estudiosos del tema como Higonnet (I990) y más recientemente Lluch (2003a, 2003b), Díaz Armas (2003, 2006), Tabernero (2005, 2006), Hanán Díaz (2OO7) o Mourão (2OI2) se adentraban en el mundo paratextual de las narraciones infantiles y juveniles dejando entrever la evolución del término que fuera definido en primera instancia por Genette.

Importante también señalar teóricos como Rosenblatt (I978, 2002), Eco (I98I), Iser (I987) y Jauss (I992) o Mendoza (1998), ya que también nos interesan los estudios que tratan lo que sucede en el acto de leer y los agentes que intervienen en este.

\section{3-Los peritextos}

Observamos que determinadas publicaciones presentan peritextos editoriales con características especiales las cuales no se contemplan en la teoría que sobre los paratextos diseñó Genette (200I). Distinguimos nuevos usos, nuevas formas e incluso nuevos espacios peritextuales que incluyen discursos relevantes para el lector en su acto de leer.

Este trato especial que les dispensan algunas editoriales parece indicar que tras él hay una intención de crear un objeto armoniosamente afinado en el que todo, absolutamente todo, cuenta. 
El lector que se aproxima a un libro no lo hace de forma inocente sin saber qué se va a encontrar en él. Se halla mediatizado por multitud de mensajes que sobre éste le han ido llegando a través de diferentes sentidos; estas informaciones le predisponen y son, en definitiva, las primeras claves que utilizará para comenzar con su interpretación de la historia. Este séquito de referencias que acompaña al texto, lo rodea, lo introduce, lo comenta y condiciona su recepción es lo que Gérard Genette denominó paratexto. Para él era el umbral del texto, una zona de transición entre el texto y lo de fuera de él y “aquello por lo cual un texto se hace libro y se propone como tal a sus lectores y, más generalmente, al público" (200I:7-8). Manifestaba que era un discurso secundario "al servicio de otra cosa que constituye su razón de ser: el texto" (2001:I6). En Palimpsestos: La Literatura en segundo grado (I989), consideraba la paratextualidad como:

(...) la relación, generalmente menos explícita y más distante, que, en el todo formado por una obra literaria, el texto propiamente dicho mantiene con lo que solo podemos nombrar como su paratexto: título, subtítulo, intertítulos, prefacios, epílogos, advertencias, prólogos, etc. (Genette, I989: II)

Unos años más tarde, en Umbrales (Genette, 200I), establecía una distinción dentro de la paratextualidad que provenía de la necesidad de tener en cuenta el lugar que ocupa un paratexto respecto al texto en sí. Considerando esta situación, señalaba dos tipos de paratextos:

- el peritexto, que se halla alrededor del texto, dentro del espacio del mismo volumen (por un lado, su título, el nombre del autor, la editorial o la colección; por otro lado, su formato, su tamaño, su encuadernación, el tacto de su portada, la letrería tipográfica,...)

- y el epitexto, que se halla asimismo alrededor del texto en sí, pero a una distancia más respetuosa (o más prudente, ya que se trata de todos aquellos mensajes que se sitúan, al menos en origen, fuera del libro como la crítica literaria, la publicidad o los premios recibidos).

El concepto de paratexto de Genette es una propuesta abierta que incluye todo aquello que alerta de algún modo al lector, sea de naturaleza icónica (ilustraciones, esquemas, fotografías, variaciones tipográficas, diagramación, etc.) o verbal (título, prólogo, índice, referencias bibliográficas, notas al pie, etc.), surja del autor (prólogo, notas aclaratorias, índices, títulos, subtítulos, dedicatorias, bibliografía, glosarios, apéndices, etc.), del editor (solapas, tapas, contratapas, etc.) o en ocasiones, de terceros (prólogos, comentarios, glosas o notas a pie).

Lluch (2003a:37) insiste en que "de hecho, el concepto de paratexto se forma a partir de un conjunto heteróclito de prácticas y de discursos de todo tipo diseñados tanto por el autor del texto, como por el editor o por el crítico literario".

Así, espacios como la cubierta, la portada o las guardas estarían incluidas en la subclasificación de peritextos siguiendo la terminología de Genette, ya que son convenciones contenidas dentro del volumen, frente a los epitextos que se encuentran fuera de éste. 
Sin embargo, el álbum y el libro ilustrado actuales desafían la definición de peritextos de Genette. Hoy en día, se puede afirmar que no todos los elementos que él considera peritextuales lo son en todos los contextos y que existen creaciones que elevan algunos peritextos a otra categoría debido a la relación estética y semántica que mantienen con la obra como unidad. Del mismo modo, se apreciaría que elementos que por definición eran generados por el editor, ahora son generados por el autor-ilustrador. Tabernero (2006:83) incide en esta idea afirmando que "es necesario plantear, al menos en lo que concierne al álbum y al libro ilustrado, la posibilidad de (...) conferirle (a la ilustración) una denominación nueva que no la vincule a lo que Genette identificó como paratexto".

Diversos estudios confirman la importancia de estos elementos en la gestación del proyecto literario por considerarlos elementos participantes en el proceso de interpretación.

Así, Shulevitz (I985) afirma que a la hora de crear este tipo de obras todo ha de tenerse en cuenta.

In order to write and illustrate a children's book, you must take everything into consideration including its physical structure (...). The book has to be integrated into a single organic entity whose parts are in harmony with each other and the whole. (Shulevitz, 1985:II3)

Y en la misma dirección camina Sipe en su artículo Picturebooks as aesthetic objects (20OI), cuando mantiene que cada una de las partes de un libro-álbum que haya sido cuidadosamente elaborado contribuye a la elaboración de una "experiencia significativa y unificada":

With the book in our hands, we should be able to understand how the choices involved in the size and shape of the book, the dust jacket, front and back covers, endpapers, title page, and front matter-the peritext of the picturebook (Genette, I982)-all work together to convey a meaningful and unified experience. (Sipe, 200I:27)

Consideramos la lectura un proceso de interacción entre la obra y el lector, un lector que es componente activo y debe estar atento a las indicaciones que le brinda el texto y dotarlas de significado (Mendoza, I998).

En la vertiente más didáctica y con referencia a la labor de los docentes en las aulas, subrayamos el trabajo de Sipe y Brightman (2005) Young children's visual meaningmaking during readalouds of picture storybooks donde lanzan una llamada de atención a los maestros los cuales, creen, deberían enseñar a los estudiantes a considerar el álbum como un objeto estético en el que todo, incluso el color de las guardas, forma parte de él.

In this way, they -the teachers- could (over time) teach children to consider picturebooks as aesthetic objects, in which every part of the total design (for example, the color of the endpages) is 
the result of an artistic decision, thereby encouraging critical thinking through building hypotheses about the decisions. (Sipe y Brightman, 2005:359)

Y continúan afirmando que una vez que los lectores conozcan las convenciones del diseño de estas publicaciones, el vocabulario referente a sus peritextos y sus funciones podrán apreciar cómo se utilizan a favor de la historia y cómo le ayudan en la construcción de sentido.

Lluch concluye su artículo Textos y paratextos en los libros infantiles (2003b) alertando sobre la relevancia de los paratextos y cómo contribuyen a la formación de lectores.

(...) debemos ser conscientes de su importancia en la literatura infantil, ya que un lector con competencia en plena fase formativa puede realizar hipótesis interpretativas sobre el texto literario a partir de la información que le facilitan. Es un hecho aceptado que cuando más información tenemos mayores posibilidades hay de elegir el relato que nos gustará más y de facilitar la comprensión. Por lo tanto, un adecuado aprendizaje de la lectura de esta información ayudará a una mejor comprensión del texto porque podrá establecer predicciones a la vez que podrá elegir más adecuadamente el título. Ahora bien, es necesaria una concienciación de todas las partes implicadas para poder comprender la fuerte carga informativa que aportan. Es imprescindible desarrollar actividades para enseñar a leerlos y que autores y editores los cuiden para poder aprovechar unos elementos con tanta fuerza significativa. (Lluch, 2003b: 276)

\section{4-Partes del libro y espacios peritextuales}

L'album serait ainsi une forme d'expression présentant une interaction de textes (qui peuvet être sous-jacents) et d'ìmages (spatialement prépondérantes) au sein du support, caractérisée par une organisation libre de la double page, une diversité des réalisations matérielles et un enchaînement fluide et cohérent de page en page. (Van der Linden, 2007:87)

A continuación mostramos un escueto análisis únicamente de aquellos peritextos que se identifican con espacios o zonas y que se encuentran con frecuencia en obras ilustradas para jóvenes lectores. No es nuestra intención diferenciar entre peritexto editorial y peritexto autoral, ya que desde nuestro enfoque más holístico consideramos que en estas creaciones tanto autores como empresa editorial deben aunar criterios a favor del libro objeto y del lector modelo que ansía el autor o autores (escritor, ilustrador, escritorilustrador).

Optamos por una clasificación sencilla de estos espacios según el lugar que ocupan en relación al cuerpo del volumen: 


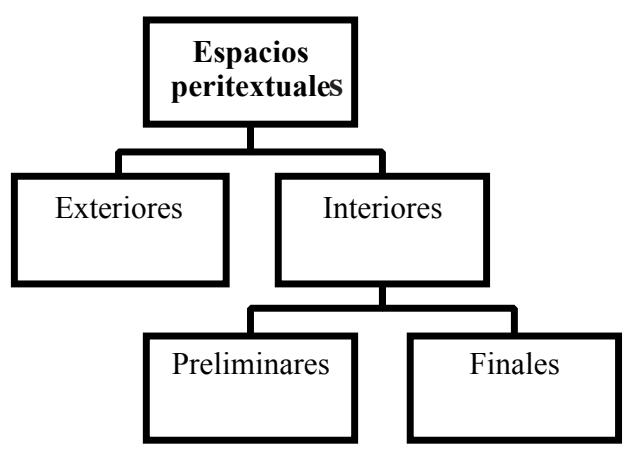

\section{A) Espacios peritextuales exteriores.}

El primer contacto del lector con la obra material lo realiza a través de estos espacios y de las informaciones que contienen. Su diseño contiene claves interpretativas de alta relevancia para el lector.

Skipping the cover and the title page is like arriving at the opera after the overture. (Moebius, I986; cit. por Sipe, 200г:25)

- CUBIERTAS o TAPAS: Son cada una de las piezas más o menos rígidas que cubren el ejemplar. En los encuadernados en rústica, comúnmente se construyen de un papel o cartulina más gruesa que las hojas que componen el cuerpo del volumen y se suelen llamar cubiertas. En los encartonados se construyen de cartón grueso forrado de papel y se denominan tapa anterior o portada exterior y tapa posterior o contratapa.

La cubierta o tapa anterior lleva impreso el nombre del autor, el título y, en la mayoría de los casos, el nombre de la casa editorial que lo publica con su correspondiente logotipo, además del sello de la colección si lo hubiera. En las obras objeto de nuestro estudio, su diseño y la información que aportan conectan directamente con el interior del libro, bien ayudado por alguna ilustración, por la tipografía, por los colores o por el formato, cosa que no siempre sucede en la literatura para adultos donde más bien es la estética normalizada de la editorial o de la colección en cuestión la que marca, en la mayoría de los casos, el diseño de la cubierta.

También las tapas posteriores merecen unas líneas en nuestro trabajo, ya que son múltiples los mensajes que trasmiten y los usos que se hacen de ellas. Al igual que en la literatura para adultos, podemos encontrar desde resúmenes que explican el contenido de la obra (Como pez en el agua, 2007), hasta textos que nos hablan del autor (:Dónde está el lobo?, 2008), pasando por la reproducción de alguna ilustración o texto del interior (El juego de las formas, 2004) o un fragmento de una crítica (El cartero simpático, 2008); sin embargo, en las obras de LIJ estas zonas también pueden albergar mensajes que apelan directamente al lector (Soñario. Diccionario de sueños del Dr. Maravillas, 2007), elementos tan asépticos y distantes como el código de barras, el ISBN o el precio totalmente integrados en la ficción del libro (Papá tatuado, 2009; El libro en el libro en el libro, 2002; Little mouse's big book of fears, 2008; El apestoso hombre queso y otros cuentos maravillosamente estúpidos, 1992), la clave para completar el círculo narrativo de 
la historia (Ser quinto, 2005; Los tres cerditos, 2005) o varias de estas informaciones a la vez, como sucede en El increíble niño comelibros (2007) donde la advertencia al lector convive con el mordisco que el protagonista ha propinado al libro.

La aparición en la cubierta de una ilustración que invade el lomo y continúa por la contracubierta es una característica muy frecuente en la LIJ ilustrada que consigue crear un nuevo espacio peritextual al que denominaré cubierta continua y que es digna heredera de la doble página (unidad básica espacial en el álbum). Recordemos obras como Dónde viven los monstruos (2009) o El árbol rojo (2005) entre otros muchos.

- SOBRECUBIERTA (o camisa) y SOLAPA (de sobrecubierta o de tapa): Aunque no son espacios usuales en la literatura infantil y juvenil, en ciertos diseños su inclusión aparece acompañada de una intencionalidad exquisita y sobradamente justificada como pudiera ser el caso de El libro en el libro en el libro (2002), El contador de cuentos (2009) o Korokoro (2009), álbum este último que incluye además un fajín cuya función no es la de indicar el premio ganado o los ejemplares vendidos, como es lo habitual, sino que actúa como portada exterior y página de créditos.

\section{B) Espacios peritextuales interiores.}

En el interior de algunas obras de LIJ no es tan sencillo detectar los espacios peritextuales como en el exterior. Aquí algunas partes se confunden y aunque en forma se ciñen a la definición clásica de peritextos, su función nos indica que desde ese momento y definitivamente la historia comienza. Encontramos un significativo número de ejemplares donde ciertas zonas peritextuales se introducen en el cuerpo del libro, o dicho de otra manera, donde la trama comienza en las páginas preliminares y convive con peritextos como los créditos o la dedicatoria. Prueba de esta simbiosis sería la primera página ilustrada de Sombras (2OIO). Del mismo modo, la historia puede terminar en una zona peritextual, como sucede en el álbum Tse-tsé (2000) donde el final comparte espacio en las guardas traseras con la revelación del número de ejemplares de la tirada en cuestión. Destacamos cómo, en ciertas producciones, los textos que en estas zonas se contemplan comparten tipografía con los del resto del volumen y que incluso los colores (y si la hubiera, la ilustración del fondo de página) tendrían una correlación con el interior. Un ejemplo de álbum en el que se advierten muestras de estas conexiones sería El increíble niño comelibros (2007).

\section{B.I. Espacios preliminares.}

Existe una gran tradición vinculada al tratamiento de cada una de estas páginas, al orden en que se disponen y a las indicaciones que contienen, normas que las obras más innovadoras van infringiendo a favor de su propio discurso ficcional y/o metaficcional. Observamos unos pliegos preliminares que han dejado de ser considerados como zona de protocolo con escaso poder para captar la atención del lector y pasar a formar parte de la propia historia del libro. 
- GUARDAS DELANTERAS: En muchos volúmenes, en lugar de guardas delanteras y traseras se insertan autoguardas (Martin, 1994:I75) que abaratan los costes y están formadas por la primera y última hoja de los cuadernillos primero y último respectivamente. Como han demostrado diferentes estudios (Sipe y McGuire, 20o6; Ramos, 2007; Bosch y Durán, 2OII; Consejo, 2OII), las guardas son zonas versátiles en las que podemos encontrar todo tipo de códigos, texturas, funciones e informaciones que ocupan un lugar especialmente privilegiado en el proceso de reconstrucción de significados. Sipe (200I:26) recordaba las palabras de Hillenbrand quien comparaba las guardas con el telón de un escenario teatral. Nosotros completaríamos la comparación añadiendo que en numerosas ocasiones los actores comienzan la función en el proscenio antes incluso de que se levante el telón. Un claro ejemplo de este caso sería Sombras (20I0).

- PORTADILLA o ANTEPORTADA: Originariamente el texto de la portadilla estaba limitado a la forma breve del título y en el caso de una colección, a su nombre. También se solía añadir la marca del editor y en cuanto a los caracteres utilizados, éstos solían ser de menor tamaño que los utilizados en la portada.

No obstante, localizamos diseños en los que la portadilla no contiene palabras, sino ilustración lo que invita al lector a que se detenga y continúe formulando expectativas. Este nuevo espacio que reemplaza a la portadilla clásica se detecta con insistencia en determinadas editoriales y determinados autores. Valgan como muestra numerosos álbumes de Oliver Jeffers.

- PORTADA y CONTRAPORTADA: Éstas forman una doble página enfrentada. A la portada igualmente se la denomina portada interior o página de tútulo.

La contraportada (entendida como cara posterior de la portadilla y en su defecto, de la guarda al aire delantera) ha soportado multitud de textos a lo largo de la historia de la encuadernación. Hoy en día, hay cierta tendencia a rellenar esta zona con los créditos, la dedicatoria, alguna ilustración o incluso, en las obras de LIJ más trasgresoras, elementos narrativos explícitos como un diálogo entre dos personajes (El apestoso hombre queso y otros cuentos maravillosamente estúpidos, 1992).

En la portada, aparte del autor, el título y el editor, se tiende a incluir alguna imagen que con cierta frecuencia se desborda ocupando la doble página, como ocurre en Los tres bandidos (2007) o El misterioso caso del oso (2008) donde además los créditos de la contraportada se presentan en forma de caligrama representando un árbol.

\section{B.2. Páginas finales.}

- Tan solo destacar la aparición de las GUARDAS TRASERAS y el potencial que a muchas de ellas se les confiere como una zona narrativa más donde concluir la historia o, en ocasiones, donde se reconduce al lector al inicio de la misma. De nuevo mencionamos el estupendo álbum de Oliver Jeffers El misterioso caso del oso (2008) o la creación metaficcional de Emily Gravett Little mouse's big book of fears (2008). Bien es verdad 
que a veces estos pliegos representan una zona polivalente donde incorporar el final de la historia a la vez que los títulos de crédito, dedicatorias, colofones, índices o breves bibliografías del autor como en En la noche oscura (2OI2). Cómo no mencionar de nuevo el álbum metaficcional El apestoso hombre queso y otros cuentos maravillosamente estúpidos en cuya guarda trasera se hallan los títulos de crédito y, camuflados en estos, un divertido juego de palabras y una advertencia al final sobre los derechos del autor:

Ilustraciones aliñadas al óleo y al vinagre. La reproducción total o parcial de esta obra no puede realizarse en manera alguna ni por ningún medio sin consentimiento previo y por escrito de la editorial o de los propietarios del copyright. Todo aquel que sea sorprendido contando alguna de estos cuentos maravillosamente estúpidos recibirá una visita en persona del Apestoso Hombre Queso. (Scieszka y Smith, 1992)

\section{CUADRO RESUMEN DE LOS ESPACIOS PERITEXTUALES ANALIZADOS}

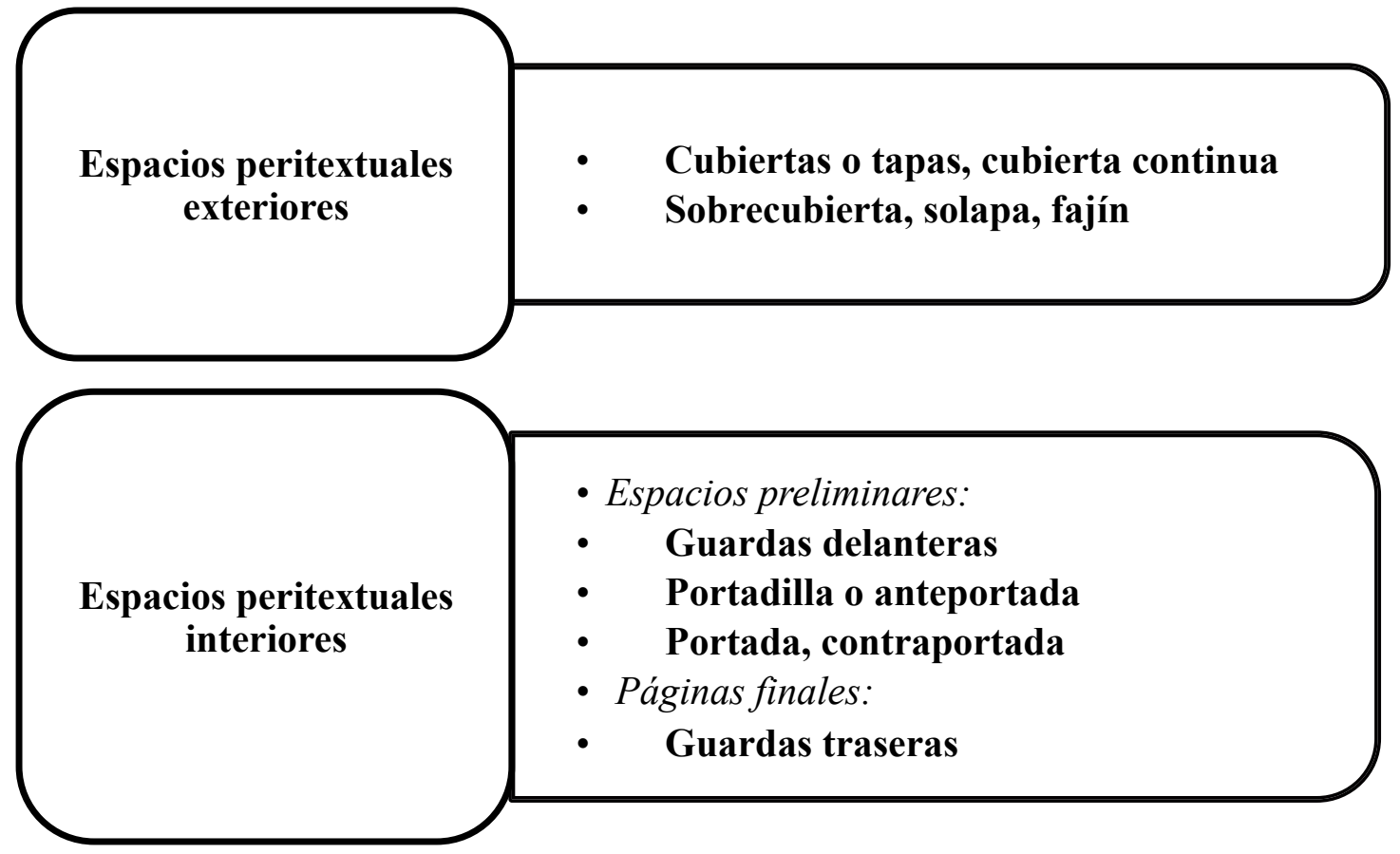




\section{5-A modo de conclusión}

Tras la revisión realizada de los espacios peritextuales que con mayor frecuencia encontramos en el panorama actual de la LIJ ilustrada, resulta innegable afirmar que el libro es un objeto vivo y como tal ha ido evolucionando a lo largo del tiempo; así, ciertas normas editoriales más o menos tácitas y ancladas a la tradición como pudieran ser el orden de presentación de las páginas preliminares, los mensajes que revelan los diferentes espacios peritextuales o las competencias que se les asignan son en la actualidad quebrantadas por la literatura infantil y juvenil, una literatura que siembra la subversión y la experimentación en muchos campos y que se redefine y reinventa día tras día.

Es evidente que esta libertad que ejercen autores y editores de libros infantiles ilustrados en cuanto al terreno peritextual contribuye a caracterizar estas obras como objetos estéticos, artísticos, de diseño global donde cada detalle cuenta para crear ese todo armonioso del que hablaban Shulevitz (I985) o Sipe (2OOI).

Y no solo se trasgreden estándares peritextuales en favor de la estética, sino también, como ya hemos visto, en favor de la historia. Es cierto que el peritexto alerta (Genette, 2OOI), ayuda a elaborar conjeturas interpretativas (Lluch, 2003b; Sipe y Brightman, 2005), sustenta implicaciones significativas (Nodelman, I988), "animan” al texto y le dan vida (Higonnet, I990), pero también encontramos ciertos espacios peritextuales que van más allá, que brindan claves interpretativas tan decisivas que consiguen mimetizarse con el texto en sí.

La metaficción, la intertextualidad o la multimodalidad son características genéticas de estas lecturas que frecuentemente dan pie a licencias que la literatura para adultos no permite y que consiguen que materia y forma aúnen esfuerzos al servicio de la obra. Estrategias como la concepción de la contracubierta o de la guarda trasera como espacios propicios para completar el círculo narrativo de una historia son inconcebibles en la literatura para adultos.

Genette afirmaba que el peritexto se halla alrededor del texto, por lo que se infería, si no una gran distancia, sí una frontera que separaba escrupulosamente el uno del otro. Hoy por hoy sostenemos que esa frontera se ha ido desdibujando y, en ocasiones, ha llegado a desaparecer.

Todo esto nos conduce a pensar en un proceso de textualización de los peritextos cuando actúan claramente como una estrategia narratológica más que se incorpora al discurso literario, cuando los espacios peritextuales dejan de ser espacios marginales y pasan a un primer plano mimetizándose con el tradicional espacio interior del volumen. Ya no son solo una aproximación al texto o un espacio liminal (Turner, r969), sino que pueden llegar a ser elementos necesarios de interpretar para construir y avanzar en nuestro proceso de lectura.

Entendemos que estos cambios en los modos de contar afectan directamente al lector modelo que subyace en estas obras, a su competencia lectoliteraria, al propio acto de leer y, cómo no, al mercado editorial. 
El lector infantil y juvenil del siglo XXI es un lector activo, adiestrado en el lenguaje icónico e hipertextual, conocedor de la lectura multimodal que supone el acto de leer ciertas obras de LIJ, exigente y al que también se le exige conocer las “normas” por las que se rigen estas nuevas producciones. Hoy su competencia lectora y literaria abarca nuevas destrezas que deberá desarrollar si quiere actualizar estos nuevos discursos literarios.

Como apuntan Lluch y Sipe, los mediadores adultos tendrán que alertar al joven lector de la existencia de estos (nuevos) peritextos y promover el pensamiento crítico con respecto a ellos. Hoy más que nunca la lectura (en su sentido más holístico) de una obra de literatura infantil y juvenil comienza en el momento en que los ojos del lector se posan sobre el libro.

El mercado editorial, sabedor de la increíble atracción que producen estas estrategias en los lectores, ofrece creaciones delicadamente editadas que convierten al libro en objeto codiciado por coleccionistas de cualquier edad. Un guarda vacía y sin color o una portada interior sin ilustración son espacios difíciles de encontrar en las publicaciones de LIJ ilustrada de nuestros días. No cabe duda de que estas publicaciones son verdaderas obras de arte diseñadas bajo la clave de la armonía, de la unidad, donde todo cuenta para guiar al lector en su acto de leer y donde toda muestra de libertad (trasgresora o no) tiene una justificación íntimamente relacionada con el discurso narrativo que ofrecen en su interior. Editores y autores comparten esta concepción y, lejos ya de la definición de peritextos de Genette, ofrecen unos espacios peritextuales al servicio del texto y, por ende, del lector. Afirmamos, en definitiva, que los elementos que rodean al texto no sólo enriquecen al libro objeto, sino que le ayudan a ser.

Recordemos las guardas ilustradas de algunos de los álbumes disponibles actualmente en el mercado, como el estampado a cuadros de la bata del papá de Browne (2002), la hoja seca de Elárbol rojo de Shaun Tan (2005), el inocente osito de la mamá de Mamá fue pequeña antes de ser mayor de Larrondo y Desmarteau (2004), el "adorable" cocodrilo Finn Herman de Letén y Bartholin (2009), los “desalmados" bandidos de Ungerer (2007), ... Estas, al igual que otras muchas, son obras en las que, desde la tapa y las guardas, el lector ha de interpretar el discurso literario que albergan los signos y señales que ofrecen, ya que de hacerlo así, éstas le proporcionarán una porción de significado que irá modelando e incorporando a la historia conforme avance en su interpretación. Creemos que esta lectura de los discursos peritextuales, multidisciplinar y multiespacial, permitirá formar lectores completos, perfeccionar su competencia lectoliteraria y descubrirles nuevos itinerarios literarios.

NOTA: A lo largo del presente artículo hemos hablado de LIJ ilustrada y no solo de álbumes ilustrados porque creemos que aunque los álbumes son un género trasgresor por definición y proclive al uso textual de los espacios peritextuales, no debemos excluir otras obras que, sin ser álbumes, no dejan de innovar, evolucionar en la concepción del objeto y ofrecer retos al lector. Citaremos como ejemplo La casa (2013) escrito por Daniel Nesquens e ilustrado por Mercè López donde la sobrecubierta se convierte en un póster que desvela la fachada de la casa por una cara y su interior, por la otra; mención aparte merecen sus ilustraciones interiores con detalles ocultos solo visibles con la ayuda de una lámina de plástico roja. 


\section{Referencias Bibliográficas}

- Bosch, E. y Durán, T. (2OII). Una tipología de las guardas de los álbumes. Anuario de Investigación en Literatura Infantil y Juvenil, g, 9-I9.

- Colomer, T., Kümmerling-Meibauer, B. y Silva-Díaz, M. C. (Coords.) (2010). Cruce de miradas: Nuevas aproximaciones al libro-álbum. Barcelona: Banco del libro - Gretel.

- Consejo, E. (2OII). Peritextos del siglo XXI. Las guardas en el discurso literario infantil. Ocnos, 7 , III-I22.

- Díaz Armas, J. (2003). Estrategias de desbordamiento en la ilustración de libros infantiles. En F. L. Viana; M. Martins y E. Coquet (Coords.). Leitura, Literatura Infantil, Ilustração: Investigação e Prática Docente (pp. I7̨-180). Braga: Universidade do Minho.

- Díaz Armas, J. (2006). El Contrato de lectura en el álbum: paratextos y desbordamiento narrativo. Primeras Noticias. Literatura Infantily Juvenil, 222, 33-40.

- Díaz-Plaja, G. (ז973). El libro ayer, hoy y mañana. Barcelona: Salvat.

- Durán, T. (2009). Álbumes y otras lecturas. Análisis de los libros infantiles. Barcelona: Octaedro.

- Eco, U. (I98I). Lector in fabula. La cooperación interpretativa en el texto narrativo. Barcelona: Lumen.

- Escarpit, R. (1972). La revolución del libro. Madrid: Alianza.

- Genette, G. (1989). Palimpsestos: Literatura en segundo grado. Madrid: Taurus.

- Genette, G. (200I). Umbrales. Buenos aires: Siglo XXI.

- Hanán Díaz, F. (2007). Leery mirar el libro álbum: ¿un género en construcción? Bogotá: Norma.

- Higonnet, M. R. (I990). The playground of the peritext. Children's Literature Association Quarterly, I5(2), 47-49.

- Iser, W. (1987). El acto de leer. Madrid: Taurus.

•Jauss, H. R. (1992). Experiencia estética y hermenéutica literaria. Madrid: Taurus.

- Lewis, D. (200I). Reading Contemporary Picturebooks: Picturing Text. London: Routledge Falmer. 
- Lluch, G. (2003a). Análisis de narrativas infantiles y juveniles. Cuenca: Ediciones de la Universidad de Castilla-La Mancha.

- Lluch, G. (2003b). Textos y paratextos en los libros infantiles. En J. I. Albentosa; P. Cerrillo y S. Yubero (Coords.). La formación de mediadores para la promoción de la lectura: contenidos de referencia del Máster de Promoción de la lectura y literatura infantil (pp. 263-276). Cuenca: Ediciones de la Universidad de Castilla-La Mancha.

- Martin, D. (ı994). El diseño en el libro. Madrid: Ediciones Pirámide.

- Mendoza, A. (1998). Tú, lector. Aspectos de la interacción texto-lector en el proceso de lectura. Barcelona: Octaedro.

- Mourão, S. (2OI2). Picturebook: object of discovery. En J. Bland y C. Ludge (Eds). Children's literature in second language education (pp. 7 $\mathrm{I}$-84). London: Bloomsbury Academic.

- Muñoz Tébar, I. y Silva-Díaz, M. C. (Eds.) (1999). El libro-álbum: Invención y evolución de un género para niños. Caracas: Banco del Libro.

- Nikolajeva, M. y Scott, C. (2OOI). How picturebooks work. New York: Garland Publishing.

- Nodelman, P. (I988). Words about pictures: The narrative art of children's picture books. Athens: University of Georgia Press.

- Ramos, A. M. (2007). Livros de palmo e meio. Reflexões sobre a Literatura para a Infáncia. Lisboa: Caminho.

- Rosenblatt, L. (1978). The reader, the text, the poem: The Transactional Theory of the Literary Work. Carbondale: Southern Illinois University Press.

- Rosenblatt, L. (2002). La literatura como exploración. Méjico D. F.: Fondo de Cultura Económica.

- Shulevitz, U. (1985). Writing with pictures: How to write and illustrate children's books. New York: Watson-Guptill Publications.

- Silva-Díaz, M. C. (2005). Libros que enseñan a leer: Álbumes metaficcionales y conocimiento literario. Tesis doctoral, Universitat Autònoma de Barcelona.

- Sipe, L. R. (2OOI). Picturebooks as aesthetic objects. Literacy Teaching and Learning, 6 (I), 23-42. Obtenido el 20 de julio de 2010 desde http://www.earlyliteracyinfo.org/documents/ pdf/doc_89.pdf 
- Sipe, L. R. y Brightman, A. (2005). Young children's visual meaning-making during readalouds of picture storybooks. National Reading Conference Yearbook, 54, 349-36r.

- Sipe, L. R. y McGuire, C. (20o6). Picturebook endpapers: Resources for literary and aesthetic interpretation. Children's Literature in Education, 37, 29I-3O4. Obtenido el 20 de julio de 20IO desde http://repository.upenn.edu/gse_pubs/38

- Sipe, L. R. y Pantaleo, S. (Eds.) (2008). Postmodern picturebooks. Play, parody and selfreferentiality. New York: Routledge.

- Tabernero, R. (2005). Nuevas y viejas formas de contar. Zaragoza: Prensas Universitarias.

- Tabernero, R. (2006). « ¿De qué sirve un libro sin dibujos ni diálogos?» Ilustración, texto e interpretación. En R. Tabernero; J. D. Dueñas y J. L. Jiménez (Coords.). Contar en Aragón. Palabra e imagen en el discurso literario infantil y juvenil (pp. 67-88). Zaragoza: Prensas Universitarias de Zaragoza; Huesca: Instituto de Estudios Altoaragoneses.

-Turner, V. (I969). The Ritual Process: Structure and Anti-Structure. Chicago: Aldine.

-Van der Linden, S. (2007). Lire l'album. Paris: L'atelier du poisson soluble.

\section{CORPUS MENCIONADO}

- Ahlberg, A. y Ahlberg, J. (2008). El cartero simpático o unas cartas especiales. Barcelona: Destino.

- Bertrand, F.; Corazza, L.; Douzou, O. y Gerner, J. (200o). Tse-tsé. Méjico D. F.: Fondo de Cultura Económica.

- Browne, A. (2002). Mipapá. Méjico D. F.: Fondo de Cultura Económica.

- Browne, A. (2004). Eljuego de las formas. Méjico D. F.: Fondo de Cultura Económica.

- Gravett, E. (2008). Little mouse’s big book offears. London: Macmillan Children’s Books.

•Jandl, E. y Junge, N. (2005). Ser quinto. Salamanca: Lóguez Ediciones.

•Jeffers, O. (2007). El increíble niño comelibros. Méjico D. F.: Fondo de Cultura Económica.

•Jeffers, O. (2008). Elmisterioso caso del oso. Méjico D. F.: Fondo de Cultura Económica.

- Larrondo, V. y Desmarteau, C. (2004). Mamá fue pequeña antes de ser mayor. Madrid: Kókinos. 
- Lee, S. (2OIO). Sombras. Cádiz: Barbara Fiore Editora.

- Letén, M. y Bartholin, H. (20o9). Finn Herman. Barcelona: Libros del Zorro Rojo.

- Müller, J. (2002). El libro en el libro en el libro. Barcelona: Serres.

- Munari, B (2012). En la noche oscura. Mantua: Corraini Editore.

- Nesquens, D. y Blanco, R. (2007). Como pez en el agua. Barcelona: Thule.

- Nesquens, D. y Mora, S. (2009). Papá tatuado. Madrid: A buen paso.

- Nesquens, D y López, M. (20I3). La casa. Madrid: A buen paso.

- Sáez Castán, J. (2007). Soñario. Diccionario de sueños del Dr. Maravillas. Barcelona: Océano.

- Saki (2009). El contador de cuentos. Barcelona: Ekaré.

- Scieszka, J. y Smith L. (1992). El apestoso hombre queso y otros cuentos maravillosamente estúpidos. Barcelona: Thule.

- Sendak, M. (2009). Dondeviven los monstruos. Madrid: Alfaguara.

- Stygryt y Ruiz, L. (2009).¿Dónde está el lobo? Méjico D. F.: Nostra.

-Tan, S. (2005). El árbolrojo. Cádiz: Barbara Fiore.

-Ungerer, T. (2007). Los tres bandidos. Pontevedra: Kalandraka.

-Vast, E. (2009). Korokoro. Cádiz: Bárbara Fiore.

-Wiesner, D. (2003). Los tres cerditos. Barcelona: Juventud. 